\title{
Research on urban and rural high-quality development based on ecological restoration of coal mining subsidence area
}

\author{
Long YANG ${ }^{1, *}$, Xiangchun $\mathrm{WANG}^{1}$, Yangyang $\mathrm{CHU}^{1}{ }^{1}$, Fei QIN ${ }^{2}$, Siyu WANG ${ }^{1}$ \\ ${ }^{1}$ China Urban Construction Design \& Research Institute Co. Ltd., Beijing, 100120, China \\ ${ }^{2}$ Xuzhou Xu-style Landscape Architecture Garden Research Institute, Xuzhou, 221009, China
}

\begin{abstract}
Ecological restoration of coal mining subsidence area is of great significance to improve the ecological and living environment, enrich the supply of ecological products, promote the green transformation of resource-based cities and the high-quality development of urban and rural areas. This paper combs the significance of ecological restoration in coal mining subsidence area to promote the highquality development of urban and rural areas, systematically expounds the realization path of ecological restoration to promote urban-rural spatial integration, cultural integration, economic integration and social integration development by taking Pan'an Lake coal mining subsidence area as a case. Finally, the highquality development evaluation index system of coal mining subsidence area based on ecological restoration is put forward, and the prospect of ecological restoration and high-quality development in coal mining subsidence area are discussed.
\end{abstract}

\section{Introduction}

China is one of the biggest countries in both coal production and consumption in the world, whose coal production and consumption exceed $45 \%$ of the world's totals ${ }^{[1,2]}$. Underground mining prevails in the coal mining industry in China. Coal mining subsidence areas, as well as sinking land and cave-ins above exhausted mines, refer to areas in which deformation or displacement in a certain range on surface layer results from mining production ${ }^{[3]}$. In China, underground mining at a rate of $90 \%$ has result in 1.1 million $\mathrm{hm} 2$ of coal mining degraded land by now, increasing at an annual increment of 30,000 40,000 hm2. These coal mining degraded land features in high coal-grain complex, eco-environment fragility and complicated types ${ }^{[4]}$. According to statistics, the area of sinking land and cave-ins above exhausted mines in the HuainanHuaibei regions reaches about $30,000 \mathrm{hm} 2$, in which the drowned area accounts for $30 \% \sim 50 \%{ }^{[5]}$. Although largescale coal mining significantly drives socioeconomic development in the regions, it is accompanied with a series of problems, e.g. unprecedented land subsidence, potential geologic hazard, land drowning, infrastructure damage, ecosystem degeneration and water environment damage.

Nowadays, Chinese economy is developing from fast-growth mode to a high-quality mode, and the relation and structure of urban and rural areas is transforming to a high grade. Urban-rural integration, a new stage of urban development, is a process of continuous change in production and living modes of urban and rural residents and also a process of mutual integration of a series of elements (e.g. population, capital and technology) in both urban and rural areas. These elements serve as resources and market for each other, finally enabling integrated development of economy, society, culture and ecology in urban and rural areas ${ }^{[6]}$. With ecological conservation and urban-rural integration are promoted, ecology restoration in coal mining subsidence areas is bound to control pollutions to water, soil and others, thus improve ecosystem functions; in addition, ecological conservation can supply more land by making good use of restored degraded land, enrich ecological goods, protect species diversity and promote green transformation of resource-oriented cities and quality urban and rural development.

\section{Promotion of ecology restoration in coal mining subsidence areas to improve quality urban and rural development}

Under the guide of high-degree economic growth target or in a mode of economic structure with low coal industry level, a series of problems arising from coal mining subsidence areas have been weakness points of the high-quality integrated development of urban and rural areas. Ecology restoration in coal mining subsidence areas is significant in improving ecosystem functions, protecting living environment of residents and sustaining industrial development.

* Corresponding author: yanglong@cucd.cn 


\subsection{Building ecological corridors and optimizing urban and rural ecological pattern}

Coal mining subsidence areas, mostly located in ruralurban fringes, have simple landscapes and poor scenes. Mining subsidence results in fragmentation of land and ecological landscape in mining areas, degrading a homogeneous and concentrated entity to complicated scattered pieces ${ }^{[7,8]}$. Ecology restoration in coal mining subsidence areas should realize multiple objectives including geologic safety, environment quality, species diversity and employment of resource by following principle of "mountain, water, forest, farmland, lake, and grassland ecosystems are a common community for life" in urban and rural areas. On the basis of making good use of site elements and space resources, ecological, low-carbon, environmentally friendly measures and proper greening with local indigenous plants can be applied. According to characteristics of environment and scene in urban and rural areas, it will shape featured ecological spaces and improve landscapes and scenes in mining subsidence areas to promote quality and stability of ecosystems.

\subsection{Making up weakness points of infrastructure and shaping featured scenes in urban and rural areas}

Coal mining subsidence areas, generally located in old industrial zones, have decrepit infrastructure like roads, drainage and power supply. To solve the problems like insufficient public services and waste/demolition of industrial heritage, ecological restoration in coal mining subsidence areas should take into account the physical spaces such as architecture, transportation, environment and landscape, and the spiritual spaces such as history, culture and lifestyle; It is also of great importance to create comfortable and livable living space, improve the facilities network and weave the transportation system, extend the cultural heritage, shape local landscape and create a pleasant environment; Also, the production and living environment in urban and rural areas should be improved, and the sense of historical and cultural identity should be enhanced, so that weakness points of infrastructure in urban and rural areas can be made up.

\subsection{Supplying good-quality ecological goods and improving living environment in urban and rural areas}

Good ecologic environment is one of the fairest public product and broadest well-being of people's livelihood ${ }^{[9]}$. Ecological restoration in coal mining subsidence areas should make up for the weakness of urban and rural ecological environment, deeply integrate the concept, principle and goal of green development into all aspects, links the whole process of urban and rural high-quality integrated development. Also, ecological restoration lay a green foundation for the modern urban-rural integrated development featured in harmonious coexistence of human and nature, make the restored space accessible to residents. And provide people with high-quality ecological products and living environment by enabling residents to enjoy the beauty of ecological landscapes and "allowing people to be close to mountains and waters and recall their rural roots with fond memory mountains, see water, remember nostalgia".

\subsection{Promoting industrial restructuring and accelerating urban and rural economic development}

Ecologic environment should be regarded as a productive force as improving ecologic environment will benefit productivity ${ }^{[10]}$. On the precondition of taking ecology as a priority, "ecologic equilibrium - economic development" can evolve in a collaborative and virtuous circle. Through ecological restoration, the circular channel of urban and rural green development is opened up, and the comprehensive carrying capacity is enhanced. Therefore, the foundation for the development of new industry and ecological industry is laid, and the integrated development level is improved. Through it, the public activity space is increased, the development of new industrial modes is promoted, and the abandoned land is recovered into urban ecological garden, science popularization base, residential land, agricultural /forestry lands and other functional land. Such measures not only speed up the green transformation of production and life modes, but also energize the high-quality development of urban and rural areas, forming modernization featured in harmonious coexistence of human and nature.

\section{Approach of driving high-quality regional development by ecology restoration in coal mining subsidence areas}

High-quality urban-rural development is based on good ecologic environment and green development. Ecology restoration in coal mining subsidence areas drives urbanrural cultural integration by regional featured culture as a carrier, and accelerates urban-rural economic integration in support of green industries, and promotes urban-rural social integration centered on comprehensive regional development, finally realizing high-quality integrated development of urban and rural areas (as shown in Figure 1). The area of Xuzhou Pan'an Lake Wetland Park was a coal mining subsidence area caused by Quantai Coal Mine and Chishan Coal Mine. Its total planned restoration area is $52.87 \mathrm{~km} 2$ and the core area was $15.98 \mathrm{~km} 2$ (including sinking land and cave-ins of $11.6 \mathrm{~km} 2$ ). Pan'an Lake is a coal mining subsidence area with the longest subsidence period, the largest area and the severest destructiveness within Jiawang District and also the largest coal mining subsidence area in Xuzhou. By ecology restoration and post-restoration planning, the derelict land became a "green lung" for cities, the submersed land turned to fertile land, and the waste yards turned to construction land. As a result, the utilize 
rate of land resource was improved greatly. Such ecology restoration case has been a countrywide sample of coal mining subsidence treatment and resourceexhausted city transformation ${ }^{[11]}$. Taking the ecology restoration of the Pan'an Lake region in Xuzhou as a case, this paper probes into the approach to drive high-quality regional development by ecology restoration in coal mining subsidence areas.

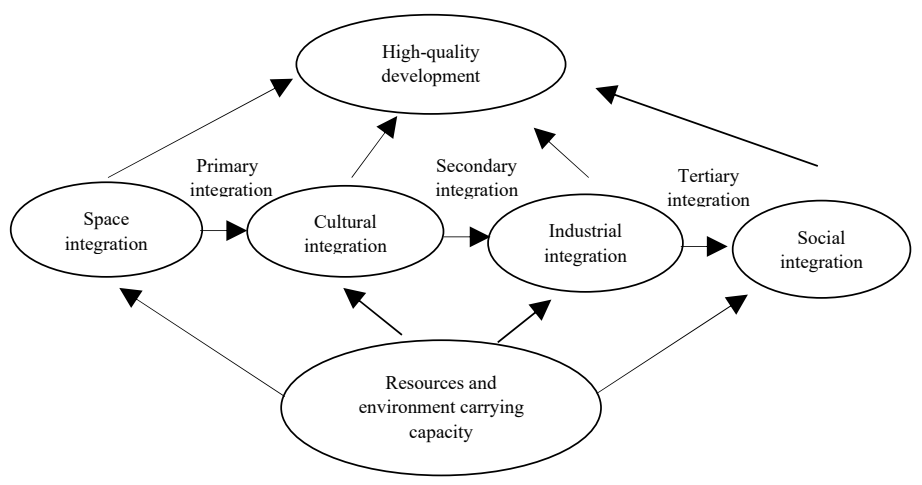

Fig. 1. Approach to drive high-quality urban-rural development by ecology restoration in coal mining subsidence areas

\subsection{Holding on to the bottom line of green ecology and promoting urban-rural space integration}

On the base of eliminating geologic hazards, ecology restoration in coal mining subsidence areas gives the overall planning for mountain, water, forest, farmland, lake, and grassland ecosystems in the ecology, farmland and industry/mining site. Green development measures were taken such as cyclic resources utilization, energy conservation, emission reduction and cooperative governance, and build a phytocommunity adaptive to surrounding environments, to improve the overall service functions of ecosystem and enhance a safe and stable regional ecosystem. In the coal mining subsidence areas where the overall ecological environment quality is good and the landscape is unique and beautiful, the ecological functions should be restored by natural means, and the ecological environment and landscape shall be protected. To achieve the objective to restore the available state of land, filling and non-filling managements are carried out for land consolidation in coal mining subsidence areas ${ }^{[12]}$. For a small number of mining areas where coal beds may still be re-mined, the surface may have new collapse and residual sinking. To deal with such challenge, treatment and reclamation elevation control is carried out with "design of compensation " in the "look-ahead management mode" in the Xuzhou-Huainan region based on subsidence predication in coal mining areas. By two-year comprehensive ecological improvement, the Pan'an Lake landscape greening and restoration project has completed $430 \mathrm{~km} 2$ of land improvement. The core area of the wetland park has reached $15.98 \mathrm{~km} 2$, with a total of 353 species (including varieties) of plants belonging to 227 genera and 97 families. As a result, the Pan'an Lake Park region has become an ecological corridor connecting Jiawang District with the main urban area of Xuzhou ${ }^{[11]}$.
Living suited plants are selected according to soil physical-chemical properties and site types. 160,000 arbors, 1,000,000 $\mathrm{m} 2$ of arboret and vegetation cover and $980,000 \mathrm{~m} 2$ of aquatic plants are planted, enabling the Pan'an Lake region to a new ecologic carrier featured in clean water, green mountains and beautiful landscape [14].

\subsection{Developing regional featured scenes and promoting urban-rural cultural integration}

In ecology restoration, regional features should be developed, avoiding over-emphasizing greening but omitting others. On the basis of ecological environment improvement, coal mining subsidence areas should develop their regional features, reasonably arrange the functional areas, and make the restoration effect more vital. 1) Relying on the diversified topography and habitat conditions of lake, river, gully, pond, field, ridge, embankment and mountain in the coal mining subsidence area, combining points, lines and surfaces of them and strengthening the unique natural landscapes or typical geographical features. Plane and vertical land control planning shall be formulated according to the objectives of geomorphy, ecology and landscape restoration. In Xuzhou Pan'an Lake Wetland Park, water systems are connected, forming catchment basins and connected water areas; A water space series with rich levels, landscape dimensions and vegetation environment is formed by a combination of design while a cluster of diverse natural and cultural landscapes is built, so that a harmony of human, animals and nature was achieved. 2) Reasonably highlighting the unique human landscape features on the basis of fully excavating, sorting out and refining the farming culture, industrial civilization, folk customs, traditional crafts, and other historical and cultural elements in the coal mining subsidence area. For example, Pan'an Culture Island is developed based on Pan An related historic culture, which includes ancient-style cultural streets, temples and civil culture and a featured building complex integrating vacationing, catering and entertainment rendered by Pan An's anecdotes. Furthermore, Shen Nong Manor carries forward Chinese traditional agriculture culture through Shen Nong sculpture. The 24 solar terms sculptures in the folk square reflect the Chinese nation's thinking about nature and human beings, as well as the cultural thought of conforming to the four seasons and the harmonious unity of "heaven, earth and man". 3) Subsidence of coal fields with higher underground water level easily results in hydrological change so that improvement of wetland landscape functions is a key link in ecology restoration of coal mining subsidence areas. All classes of water areas, forest land and scenic lands are protected and an ecological landscape system of "creature - waterscape farmland" is established in the Pan'an Lake region. Next, ecology restoration emphasizes dynamic equilibrium of water system reshaping, earthwork design and land use as well as side slope pitching for lake and island banks. Featured ecological settlement is developed around bird 
habitat regions and wetland plant areas in the Pan'an Lake region. By using wetlands, bulkheads and islands, urban sponge foundation is built, and featured farmland landscapes are created at restored reclaimed farming and forestry lands within the subsidence areas ${ }^{[14]}$.

\subsection{Promoting green development transformation and accelerating urban-rural economic integration}

Treatment of coal mining subsequence, not a simple sense of "indicator increase or decrease", but a comprehensive management focusing on environment restoration and the resources revitalization, which transforms the historical burden into the resource advantages in ecological, economic and social construction, making it a driving force to promote the high-quality transformation and development of the old industrial base (Li Gang, 2018). On the base of improving ecological functions, ecological restoration of coal mining subsidence area will play a role in leading functional industries, resource utilization, cultural landscape, life services, brand building and other aspects to form "Ecology +" industrial development modes, such as wetland ecological conservation mode, new comprehensive agricultural development mode, ecoindustrial park mode, eco-leisure tourism mode and so on $^{[15]}$. Xuzhou Pan'an Lake Wetland Park has been developed to a super large urban wetland park integrating wetland natural landscapes and featured farming/folk culture landscapes, which has fostered the development potential of surrounding commerce, plantation, leisure and sightseeing agriculture, and greatly promoted the economic development in Jiawang District. Pan'an Lake wetland has been built to a national AAAA scenic spot, national wetland park, national water conservancy scenic spot, national eco-tourism demonstration base, and national wetland tourism demonstration base. It is famous as a bright ecological pearl and a green economic growth pole in Huaihai Economic Zone.

\subsection{Strengthening the joint forces of regional development to drive urban-rural social integration}

Ecological restoration of coal mining subregion area strengthen urban-rural social integration and regional development mainly by the following four joint forces: 1) Improving infrastructure. Collocation of infrastructure is a key factor affecting the industrial restructuring of coal resource-based cities. Complete infrastructure can drive the development of leading industries, and the increase of investment in infrastructure will result in the output increase of the three industries. As a result, it will promote industrial upgrading of coal resource-based cities $^{[16]}$. 2) Improving land functions. Restored shallow and stable subsidence lands are empowered with different functions, including urban housing, administrative office, commerce, public infrastructure, according to the urban-rural development and town construction under the guidance of master urban planning and rural planning. 3) Improving employment. Pan'an Lake Wetland Park employs about 1,630 employees in surrounding areas and gained the tourism revenue of CNY 3.02 billion in 2018 from zero in Jiawang District in the past ${ }^{[17]}$. 4) Improving regional development quality. Pan'an Lake Scenic Area builds a cultural tourism town of "integration of landscape and town", which is organically connected with Mazhuang Sachet Culture Town. The scenic area introduces 7 featured functions, including high-end residence, leisure vacation, entertainment, theme park, business conference, theme hotel and health movement, enabling an ecological holiday complex in Xuzhou. In addition, it drives the integration of education and human resources and promote the urban-rural social integrated development in Jiawang District. Pan'an Lake Scenic Area has attracted a large number of emerging industries with high technology content and low resource consumption to base. Nearby it, Xuzhou Shi Science and Education Innovation Zone with an area of $20 \mathrm{~km} 2$ is planned, and will become a hub for high-end talent and industries in a near future. In 2016, Xuzhou put forward the concept of Pan'an Lake Science and Education Innovation Zone and prepared Master Plan of Pan'an Lake New City and Pan'an Lake Science and Education Innovation Zone. Through education supporting industries and industries benefitting education, a scientific innovation valley is planned to be built in Xuzhou -Jiawang Economic Corridor. Coordinated with the development of the new city, it will form a central functional area with strong cohesion to transform Pan'an Lake New City from an ecological barrier to a new smart city.

\section{EVALUATION ON COMPREHENSIVE BENEFITS OF ECOLOGY RESTORATION IN COAL MINING SUBSIDENCE AREAS}

Comprehensive benefits of ecology restoration in coal mining subsidence area include ecological benefit, economic benefit and social benefit, so that the benefit evaluation indicator systems shall have these three dimensions. The ecological benefit evaluation subsystem includes such indicator systems as species diversity, environment quality, ecological landscape pattern and ecological matrix restoration; the economic benefit evaluation subsystem include such indicator systems as project investment, eco-industry development, GDP per capita increase and real estate premium; the social benefit evaluation subsystem includes such indicator systems as geologic hazard, employment, park service capacity and infrastructure construction (see Figure 2). Each indicator system under a subsystem is characterized by one or more representative indicators. 


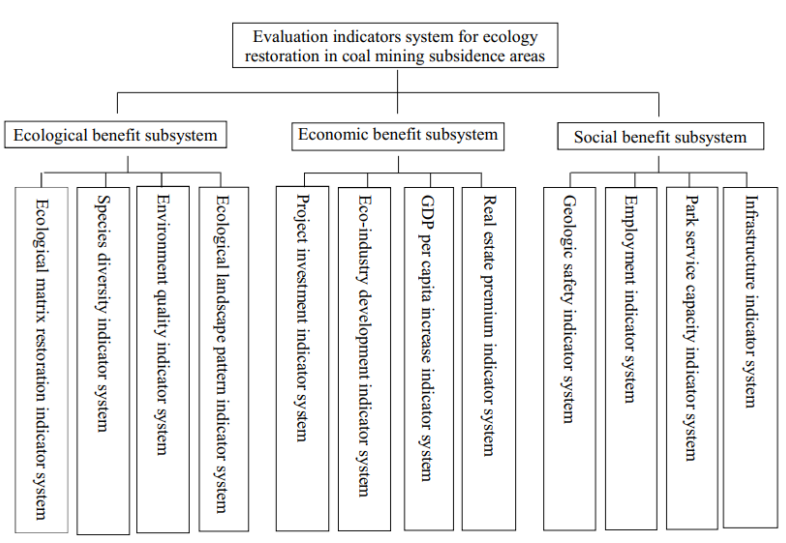

Fig. 2. Indicator systems for evaluation on comprehensive benefits of ecology restoration in coal mining subsidence areas

Following the principle of "systematicness, effectiveness, scientificity and controllability, representative indicators are selected for each indicator level. The evaluation on comprehensive benefits of ecology restoration for the coal mining subsidence areas in the Pan'an Lake region is shown in Table 1. According to Table 1, the ecology restoration in the Pan'an Lake region gets better ecological, economic and social benefits. But the uniformity of plants in the park region is lower, for example, among all arbors in the park, some tree species, like metasequoia and pond baldcypress, are planted over ten thousand but others (like bothrocaryum controversum, sinojackia xylocarpa and hovenia acerba) are less than $20^{[18]}$. Additionally, the proportion of tourists from other provinces and cities is low, so that the regional service capacity for the park needs be improved.

Table 1. Evaluation on comprehensive benefits of ecology restoration in coal mining subsidence areasof the Pan'an Lake region.

\begin{tabular}{|c|c|c|c|c|c|}
\hline $\begin{array}{c}\text { Objectiv } \\
\text { e level }\end{array}$ & $\begin{array}{c}\text { Criteria } \\
\text { level }\end{array}$ & $\begin{array}{c}\text { Indicator } \\
\text { level }\end{array}$ & $\begin{array}{c}\text { Representativ } \\
\text { e indicator }\end{array}$ & $\begin{array}{c}\text { Evaluatio } \\
\text { n }\end{array}$ & $\begin{array}{l}\text { Source } \\
\text { of data }\end{array}$ \\
\hline & \multirow{9}{*}{$\begin{array}{l}\text { Ecologic } \\
\text { effect }\end{array}$} & \multirow{5}{*}{$\begin{array}{l}\text { Species } \\
\text { diversity }\end{array}$} & Simpson index & 0.928 & \multirow{4}{*}{$\begin{array}{l}\text { Referenc } \\
\mathrm{e}^{[18]}\end{array}$} \\
\hline . & & & $\begin{array}{l}\text { Shannon- } \\
\text { Wiener index } \\
(\mathrm{H}) \\
\end{array}$ & 3.34 & \\
\hline 莺 & & & $\begin{array}{l}\text { Margalef plant } \\
\text { abundance } \\
\text { index (D) }\end{array}$ & 13.6926 & \\
\hline 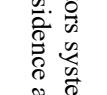 & & & $\begin{array}{l}\text { Pielou plant } \\
\text { uniformity } \\
\text { index (E) }\end{array}$ & 0.6488 & \\
\hline 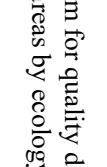 & & & \begin{tabular}{|l} 
Birds species \\
proportion of \\
this region to \\
the entire \\
province \\
\end{tabular} & $45.43 \%$ & \multirow{4}{*}{$\begin{array}{c}\text { Referenc } \\
\mathrm{e}^{[19]}\end{array}$} \\
\hline 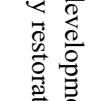 & & Environmen & $\begin{array}{l}\text { Proportion of } \\
\text { quality water } \\
\text { bodies }\end{array}$ & $100 \%$ & \\
\hline \multirow{3}{*}{ 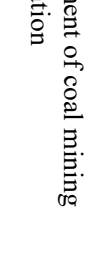 } & & quality & $\begin{array}{l}\text { Proportion of } \\
\text { good air } \\
\text { quality days }\end{array}$ & $\geq 85 \%$ & \\
\hline & & $\begin{array}{c}\text { Ecological } \\
\text { landscape } \\
\text { pattern }\end{array}$ & $\begin{array}{l}\text { Greening rate } \\
\text { (excluding } \\
\text { water body) }\end{array}$ & $81.26 \%$ & \\
\hline & & $\begin{array}{l}\text { Ecological } \\
\text { matrix }\end{array}$ & $\begin{array}{l}\text { Ecology } \\
\text { restoration rate }\end{array}$ & $100 \%$ & $\begin{array}{l}\text { Survey } \\
\text { findings }\end{array}$ \\
\hline
\end{tabular}

\begin{tabular}{|c|c|c|c|c|c|}
\hline $\begin{array}{c}\text { Objectiv } \\
\text { e level }\end{array}$ & $\begin{array}{c}\text { Criteria } \\
\text { level }\end{array}$ & $\begin{array}{c}\text { Indicator } \\
\text { level }\end{array}$ & $\begin{array}{c}\text { Representativ } \\
\text { e indicator }\end{array}$ & $\begin{array}{c}\text { Evaluatio } \\
\text { n }\end{array}$ & $\begin{array}{l}\text { Source } \\
\text { of data }\end{array}$ \\
\hline & & $\begin{array}{l}\text { restoration } \\
\text { rate }\end{array}$ & & & \\
\hline & \multirow{5}{*}{$\begin{array}{c}\text { Economi } \\
\text { c effect }\end{array}$} & $\begin{array}{c}\text { Project } \\
\text { investment }\end{array}$ & $\begin{array}{l}\text { Project } \\
\text { investment } \\
\text { scale }\end{array}$ & $\begin{array}{c}\text { More than } \\
2 \text { billion } \\
\text { CNY }\end{array}$ & \multirow{3}{*}{$\begin{array}{l}\text { Referenc } \\
\mathrm{e}^{[20]}\end{array}$} \\
\hline & & \multirow[b]{2}{*}{ Eco-industry } & $\begin{array}{l}\text { Tourism man- } \\
\text { times }\end{array}$ & \begin{tabular}{|l}
7.7 million \\
(in 2017)
\end{tabular} & \\
\hline & & & $\begin{array}{l}\text { Comprehensive } \\
\text { tourism income }\end{array}$ & $\begin{array}{l}2.3 \text { billion } \\
\text { CNY (in } \\
2017 \text { ) }\end{array}$ & \\
\hline & & $\begin{array}{l}\text { GDP per } \\
\text { capita } \\
\text { increase in } \\
\text { this region }\end{array}$ & $\begin{array}{l}\text { GDP per capita } \\
\text { increase in } \\
\text { Jiawang } \\
\text { District from } \\
2010 \text { to } 2018\end{array}$ & $\begin{array}{c}46,000 \\
\mathrm{CNY}\end{array}$ & \multirow{2}{*}{$\mathrm{e}^{\text {Referenc }}$} \\
\hline & & $\begin{array}{l}\text { Housing land } \\
\text { prices } \\
\text { increase in } \\
\text { this region }\end{array}$ & $\begin{array}{l}\text { Housing land } \\
\text { prices increase } \\
\text { in Jiawang } \\
\text { District from } \\
2010 \text { to } 2018 \\
\end{array}$ & $\begin{array}{c}2.7 \mathrm{million} \\
\mathrm{CNY} / \mathrm{mu}\end{array}$ & \\
\hline & \multirow{4}{*}{$\begin{array}{l}\text { Social } \\
\text { effect }\end{array}$} & $\begin{array}{l}\text { Geologic } \\
\text { safety }\end{array}$ & $\begin{array}{l}\text { Geologic } \\
\text { hazard } \\
\text { incidence rate }\end{array}$ & None & $\begin{array}{l}\text { Survey } \\
\text { findings }\end{array}$ \\
\hline & & $\begin{array}{c}\text { Employed } \\
\text { population in } \\
\text { this region }\end{array}$ & $\begin{array}{l}\text { Employment } \\
\text { rate of } \\
\text { working-age } \\
\text { population }\end{array}$ & $94 \%$ & $\begin{array}{c}\text { Referenc } \\
\mathrm{e}^{[22]}\end{array}$ \\
\hline & & $\begin{array}{c}\text { Park service } \\
\text { capacity }\end{array}$ & $\begin{array}{l}\text { Proportion of } \\
\text { tourists from } \\
\text { other provinces } \\
\text { and cities }\end{array}$ & $15 \%$ & $\begin{array}{c}\text { Referenc } \\
\mathrm{e}^{[19]}\end{array}$ \\
\hline & & $\begin{array}{c}\text { Infrastructur } \\
\mathrm{e} \\
\text { construction }\end{array}$ & $\begin{array}{l}\text { Infrastructure } \\
\text { improvement }\end{array}$ & Good & $\begin{array}{c}\text { Referenc } \\
\mathrm{e}^{[22]}\end{array}$ \\
\hline
\end{tabular}

\section{CONCLUSION AND OUTLOOK}

Ecology restoration in coal mining subsidence areas is an important approach to improve the urban and rural ecological environments, and also a foundation and engine to support high-quality development of economy and society in urban and rural areas. Generally, researches about ecology restoration in coal mining subsidence areas mostly focus on the technical aspects of land reclamation and ecological landscape construction and few of them show solicitude for the systematic exploration from ecological restoration to rational utilization. Relevant studies have some crossing, overlaps and variation in the concepts, research scope and technical system of land reclamation, ecological reconstruction, and ecological restoration, but unclear theoretical framework of ecological restoration ${ }^{[1]}$. To promote the ecological restoration of coal mining subregion area and other similar areas so as to better serve the high-quality integrated development in urban and rural areas, the following proposals are put forward:

(1) Highlighting biodiversity and suitability. As a part of urban and rural ecological space, ecological restoration should go beyond vegetation restoration and natural landscape greening, but organically integrating restored coal mining subsidence area into the urban and rural ecosystem according to the objectives of urban and rural species diversity protection, ecosystem function improvement and ecological product supply. Based on ecological suitability and safety of different seedling sources and varieties, the plants for ecology restoration 
of coal mining subsidence area should be indigenous plants, zonal plants with distinct regional characteristics and living suited plants, which are more suitable to build a close-to-nature community.

(2) Raising the values of ecological goods in coal mining subsequence areas. Ecology restoration in coal mining subsidence area should serve people's life and production. Besides ecological improvement functions, it should facilitate functional industries development, resource utilization, cultural landscape, life service and brand building in an integrated way. During the planning stage, ecological restoration plan should excavate and inherit the local farming culture, carry out functional fusion and industrial transformation, enhance regional land value, develop a diversified industrial system covering ecological agriculture, eco-tourism, health care and leisure, and transform development momentums to form an industrial economy of green circle.

(3) Strengthening integration of multiple departments, disciplines and fields. At present, the relevant policies and regulations for ecological restoration in coal mining subsequence areas need to be improved, the source of special funds is single and the financing mode is still lacking. Additionally, the high-level, refined ecological restoration technology is still in its infancy, and there are still deficiencies in its operation, maintenance and management supports. To establish a long-term mechanism for ecological restoration and governance, in-depth research and active exploration are still in need in financing modes, operation management, monitoring means, evaluation methods, and other aspects. In addition, the ecological monitoring and prediction technologies based on integrated $3 \mathrm{~S}$ technology, big data and cloud platform should be developed to execute a long-term, effective dynamic management for the restored ecosystems, so as to systematically improve the ecological restoration technology and promote the highquality urban-rural development.

\section{ACKNOWLEDGMENTS}

This research was funded by Science and Technology Plan, Ministry of Housing and Urban-Rural Development of the People's Republic of China, 2019 (Project No. 2019-K-142).

\section{References}

1. Xu Yan, Wang Lu, Fan Jiaqi, Qin Jiaxing. Journal of China Agricultural University. 25(07), 80-90 (2020)

2. Chang Jiang, Liu Xiangxu. China Mining Magazine. 27(07), 64-69 (2018)

3. T/CHSLA 50002-2018. Technical standard for ecological restoration in coal mining subsidence area of Huang-Huai-Hai Plain (China Construction Industry Press, 2019)

4. Guo Wenbing, Guo Mingjie, Tan Yi, Erhu Bai, Gaobo Zhao. Sustainability. 11(16), 1-34 (2019)
5. Li Shilong, Chen Xiaoxie, Shao Jia, Liu Hui, Qiu Feng, Zhu Xiaojun. Mine Surveying. 46(06), 1-4 (2018)

6. Liu Rongzeng, Zhao Liang, Chen Na, He Chun. Regional Economic Review. 05, 94-104 (2020)

7. Li Pengshan, Lu Yahui, Zhang Chao, Yun Wenju, Yang Jianyu, Zhu Dehai. Transactions of the Chinese Society for Agricultural Machinery. 47(05), 281-287 (2016)

8. Guo Jiaxin, Hu Zhenqi, Yuan Dongzhu, Liang Yusheng, Li Pengyu, Yang Kun. Journal of China Coal Society, 1-15 (2020).

9. Li Ganjie. Protect a good ecological environment, the most inclusive welfare of people's livelihood. People's daily. 2019-06-03(009) (2019)

10. Li Zujiao. Green China. 11, 36-41 (2019)

11. Chang Jiang, $\mathrm{Hu}$ Tinghao, Zhou Yao. Coal Economic Research. 39(09), 51-55 (2019)

12. Wang Qiaoni, Chen Xinsheng, Zhang Zhiguang. China's land and resources economy. 6, 23-24, 47 (2009) .

13. Sun Xielong, Bi Yongchao. Anhui agronomy Bulletin. 26(15), 119-120 (2020).

14. Wang Ziqiang, Qi lunian, Zhou Lifan. Jiangsu urban planning. 03, 25-29 (2019)

15. Sun Fayin, Wang Jiye. Journal of Zaozhuang University. 37(05), 98-104 (2020)

16. Li Xingxi. China University of Mining and Technology. (2019)

17. Liu Yuqing. China University of Mining and Technology. (2020)

18. Yang Ruiqing, Wang Qianqian, Xu Delan. Journal of Northwest Forestry University. 33(03), 285-289 (2018)

19. Li Lu. China University of Mining and Technology. (2020)

20. Yao Xueqing. People's daily, 2017-12-15 (14). http://env.people.com.cn/GB/n1/2017/1215/.html.

21. Quan Gang, Tian Junhong, Jia Wang, Xuzhou. Natural resources communication. 15, 39-41 (2020)

22. Liu Yuqing. China University of Mining and Technology. (2020) 